\title{
Pyridinoline to Creatinine Ratio Measurement
}

National Cancer Institute

\section{Source}

National Cancer Institute. Pyridinoline to Creatinine Ratio Measurement. NCI Thesaurus.

Code C147426.

The determination of the ratio of pyridinoline compared to creatinine present in a sample. The measurement may be expressed as a ratio or percentage. 